DOI: 10.12731/2077-1770-2019-5-151-160

УДК 811.161.1: 616.21

\title{
СЛОЖНОПОДЧИНЕННЫЕ ПРЕДЛОЖЕНИЯ С ИНТЕРПОЗИТИВНОЙ ПРИДАТОЧНОЙ ЧАСТЬЮ В ТЕКСТАХ МЕДИЦИНСКОЙ СПЕЦИАЛЬНОСТИ (НА МАТЕРИАЛЕ ОТОРИНОЛАРИНГОЛОГИИ)
}

\author{
Мирзоева В.М., Аксенова Е.Д., Мирзоева Е.З.
}

Состояние вопроса. Сложившиеся подходы клингвистическому анализу сложных предложений требуют переосмысления, так как классическое понимание роли интерпозиции в синтаксисе сложного предложения ограничивает ее функциональное описание семантически и конструктивно. В данном исследовании представлен авторский взгляд на функиионирование сложноподчиненных предложений с интерпозитивной придаточной частью в текстах медицинской специальности «Оториноларингология», в связи с чем не только освещаюттся разные трактовки понимания интерпозиции в лингвистике но и подробно рассматриваются средства маркированности частей сложного предложения, их особенности функциионирования в медицинском тексте.

Методология проведения работы. Использование методов научного описания, наблюдения и статистического анализа позволило получить достоверную информацию о семантико-синтаксической структуре данного типа предложений и их специфике в текстах медииинской специиальности.

Результаты. Лингвистический анализ сложноподчиненных предложений на материале медицинских текстов показал: интерпозитивное положение придаточной части имеет разное формальное выражение, что является основанием для классификации типов сложных предложений по виду маркированности их придаточной части. Рассмотренный материал свидетельствует о том, что интерпозицчия придаточной части весьма неоднозначна, но вместе с тем выявляет специфику научного (медицинского) текста специиальности. 
Область применения результатов. Полученнье результаты могут быть использованы не только для дальнейших исследований научного (медицинского) текста, но и важны в педагогической практике обучения иностранных студентов-медиков.

Ключевые слова: сложноподчиненное предложение; интерпозиция придаточной части; коммуникативно-семантические отношения; оториноларингология.

\section{COMPLEX SUBJECT SENTENCES WITH INTERPOSITIVE SUBORDINATE CLAUSE IN MEDICAL TEXTS (BASED ON OTORHINOLARYNGOLOGY)}

\section{Mirzoeva V.M., Axenova E.D., Mirzoeva E.Z.}

State of the problem. Existing approaches to the linguistic analysis of complex sentences require rethinking as the classic comprehension of the role of interposition in the syntax of the complex sentence semantically and meaningfully limits it functional description. Author's attitude towards the functioning of complex subject sentences with interpositive accesory part in the medical texts on otorhinolaryngology is presented in this paper so not only differents views on interposition in the linguistics is being explored but also the means of marking complex sentences parts and its functioning special features in the medical texts are being thoroughly examined.

Methodology. Usage of scientific descriptions methods, observation and statistic analysis allowed to get accurate information on semantic and syntax structure of such sentences and their specifics in the medical texts.

Results. Linguisic analysis of complex subject sentences based on the medical texts showed that interpostive state of the accessory part may have different formal expression what may be the reason to classify different complex sentences types by the marking of their accessory parts. Explored material shows that the accessory part interposition is quite ambiguous but along with it shows the specifics of scientific medical text. 
Area of results application. The results may be used not only for following research of scientific (medical) text but are also important in the pedagogical practice of teaching foreign medical students.

Keywords: complex subject sentence; interposition of subordinate clause; communicative and semantic relations; otorhinolaryngology.

В большинстве современных классификационных описаний сложноподчиненного предложения позиция придаточной части по отношению к главной рассматривается как один из существенных структурных признаков различных типов сложноподчиненного предложения: «Каждое предложение с грамматической точки зрения представляет внутреннее единство словесно выраженных его членов, порядка их расположения и интонации» [4, с. 289].

Вместе с тем, если вопрос о препозиции и постпозиции придаточной части рассматривается во всех работах как факт структуры сложноподчиненного предложения, вопрос об интерпозиции придаточной части в лингвистической литературе решается неоднозначно.

При широком понимании интерпозиция трактуется как включенность одной части сложного предложения в другую. Согласно такому пониманию интерпозитивной считается любая придаточная часть, стоящая внутри главной. Так представляет интерпозицию «Грамматика русского языка» [8].

Более узкое понимание связывает интерпозицию с категориями вводности и присоединительности: только та включенная в главное предложение придаточная часть интерпозитивна, которая носит характер вводности и является добавочным сообщением по отношению к главной части. Интерпозитивная придаточная часть, соединяясь с главной по правилам данного типа сложного предложения, «всегда сохраняет свое категориальное значение. Поэтому значение вводности, которое может проявляться с различной силой, имеет обычно добавочный, сопровождающий характер и прямо связано с интерпозицией придаточной части» [6, с. 98].

Например: Анализ информативности симптомов заболевания для отоларинголога, несмотря на то, что симптомы зачастую 
функиионально не связаны друг с другом, представляет собой сложную медико-биологическую задачу [9; с. 37].

Калорические пробы, во время которых осторожно вливают холодную или горячую воду, дают возможность обследования ушей по отдельности [2; с. 32].

Истинное вестибулярное головокружение обычно проявляется ощущением вращения в голове, словно пациент находится в иллюзии вращения окружаюших предметов, сопровождается тошнотой, нарушением равновесия [3; с. 107].

В приведенных конструкциях детерминантного типа придаточные части, сохраняя свойственное им категориальное значение (отвергаемое условие, время, сравнение), кроме того, имеют еще и оттенок вводности, добавочности сообщения.

Как правило, «в научных текстах медицинского профиля, в частности оториноларингологии, приоритетное положение занимают показатели онтологической возможности, наиболее подчеркнуто представляющие семантику потенциальности» [1; с. 156].

Таким образом, узкое понимание ограничивает интерпозицию семантически (она связывается с выражением отношений выделительности и добавочности) и конструктивно: она фиксируется только в сложноподчиненных предложениях расчлененной структуры, в которых оттенок вводности возможен, так как придаточная часть является факультативным распространителем главной части.

При лингвистическом анализе сложных предложений с фиксированным порядком частей на материале текстов оториноларингологии обращает на себя внимание следующий факт: одна часть может быть маркирована как несамостоятельная в смысловом и грамматическом отношении и сигнализировать о другой как обязательной в пре- или постпозиции по отношению к ней. В этом случае речь идет о предложениях с препозитивной или постпозитивной маркированной частью: Поражение может затрагивать любой отдел синуса, ибо абсиесс может не ограничиваться стенкой сигмовидного синуса и распространяться экстрадурально в среднюю и заднюю черные ямки. [2; c. 75] Союз ибо маркирует постпозитивную придаточную часть. 
Если обе части являются помеченными как синсемантичные или грамматически несамостоятельные, конструкции рассматриваются как предложение со взаимно маркированными частями: Процессор анализирует сигнал и вырабатывает импульс так, что кохмарный имплант возбуждает нервные окончания. [2; с. 101] Но применять противоотечные средства, муколитики надо так, чтобы их эффективность была велика [2; с. 55].

Указательное слово так и союзы что и чтобы, соответствующие ему, составляют пару структурно необходимых компонентов сложноподчиненного предложения, обусловливающих постпозицию придаточной части, и представляют взаимную маркированность частей. Придаточная часть в таких предложениях может быть только постпозитивной. Эти средства связи имеют устойчивый характер, и один из компонентов связи непременно предполагает наличие другого, т.е. сила маркированности компонентов одинакова, поэтому взаимная маркированность частей ярко выражена.

Вторую разновидность взаимной маркированности представляют составные расчлененные союзы: Если симптомы понимать в признаковом т-мерном пространстве, то задача кластерного анализа формулируется как разбиение совокупности симптомов на однородныле кластеры. [9; с. 79] Хотя характерным признаком хронического тонзиллита является нерезкая болезненность подчелюстных и затылочных лимфатических узлов, но ряд исследователей указывает на увеличение верхних шейных лимфатических узлов [9; с. 22].

Первый компонент составного союза маркирует придаточную часть (если, хотя), а второй (то, но) - главную. Придаточная часть в конструкциях такого типа препозитивна. Компоненты составных союзов, маркируя обе части, обладают неодинаковой силой маркированности. Более веским маркером является второй компонент, который актуализирует главную часть и обязательно предполагает препозитивную придаточную часть, но он факультативен.

Рассматриваемые нами конструкции присубстантивного типа позволяют выделить еще один вид маркированности: о позиции придаточной части свидетельствуют одновременно два показателя, 
находящихся в главной части, обрамляющих придаточную часть и создающих ее серединную позицию. В сущности, в предложении возникает двойная маркированность; она отличается от взаимной тем, что ее компоненты не предполагают друг друга, второй показатель является повторяющимся. В таких построениях придаточная часть в известной мере приобретает характер дополнительного сообщения и может быть заменена вставной конструкцией. Эта семантическая осложненность и грамматическая обозначенность придаточной части позволяет рассматривать ее как интерпозитивную. Например: Острый ринит обусловлен вирусной инфекцией, которая передается воздушно-капельнылм путем - оттого острый отит является очень контагиозным, - это инфекционное воспаление ускоряется при снижении резистентности организма [2; с. 129].

В присубстантивных предложениях, осложненных лексико-синтаксическим повтором, структурное назначение опорного слова определять форму и значение придаточной части - сочетается с его участием в актуализации предложения: четко определяя границы придаточной части, повторяющееся опорное слово подчеркивает коммуникативную значимость сообщаемого в главной.

Проведенный анализ медицинских текстов показал: интерпозитивное положение присубстантивной придаточной части имеет разное формальное выражение. Повтор в качестве грамматического показателя интерпозиции придаточной части может иметь разное строение, в связи с чем существует несколько вариантов соотношения между исходным обозначением опорного члена и повтора. Так, повтор точно воспроизводит обозначение исходного члена - словоформу или словосочетание: Двусторонний паротит, который у детей разрешается самостоятельно, паротит, обычно вызываемый вирусом свинки, у взросльх развивается чаще на фоне истощения, обезвожсивания, отсутствия гигиены полости рта [2; с. 201].

Местоименно-указательный компонент исходного обозначения опорного члена в повторе, в свою очередь, замещен другим место-

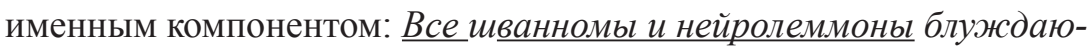
щего нерва проявляются растущим объемным образованием в об- 
ласти шеи, когда происходит поражение нервов основания черепа, эти шванномы и нейролеммоны требуют детального обследования с визуализащией основания черепа [2; с. 181].

Следует обратить внимание и на следующие замещения:

1. Лексический компонент исходного обозначения опорного члена в повторе замещен местоименным компонентом: $\underline{\underline{H}}$ только метод обучающего алгоритма «деревья классификачии», который помогает диагностировать хроническое заболевание, и только этот метод позволяет практическим врачам отказаться от общепринятых субъективных классификачий хронического тонзиллита [9; с. 3].

2. В повторе обозначение исходного члена дополнено указательным местоимением: К редким осложнениям относятся абсиесс или флегмона орбитальной сетчатки, которые возникают чаще всего при проколе через средний носовой проход, - эти осложнения требуют поэтому обоснованного подхода к пробному проколу [5; с. 125].

3. Повтор включает лексические компоненты, которых нет в исходном обозначении опорного члена: Te деформации носа, которые разрушают хрящи носа, те аномалии носа, которые приводят к изменению поверхности костей, могут быть врожденными или обусловленными травмой [5; с. 119].

4. Повтор содержит только часть лексических компонентов исходного обозначения опорного члена: риногенный встречается в виде слипчивого или кистозного прочесса, арахноидит отмечается чаще в передней черепной ямке [5; с. 143].

5. Исходное обозначение опорного члена не повторяется, а замещается синонимичным выражением: Даже те методики осмотра, которые необходимы, эти тактики необходимо переоченить для точной диагностики хронических заболеваний среднего уха [2; с. 24].

Двойная маркированность интерпозиции придаточной части имеет место и в других типах сложноподчиненных предложений, например: 
А) в синтаксических конструкциях изъяснительного типа: $\underline{A O}$ том, что саркоидоз является системным заболеванием, что имеет неизвестную этимологию, - об этом необходимо помнить при саркоидном поражении носа [2; с. 134].

Б) в местоименно-соотносительных конструкциях отождестви-

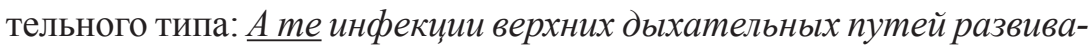
ются очень часто, те во многих случаях осложняются вторичной бактериальной инфекцией [2; с. 143].

Рассмотренный материал свидетельствует о том, что интерпозиция придаточной части весьма неоднозначна: в одних конструкциях сложноподчиненных предложений она отражает только зависимость придаточной части от главной, в других - связана с выражением определенных коммуникативно-семантических отношений.

Безусловно, сложноподчиненные предложения с двойной маркированностью позиции придаточной части гораздо частотнее в произведениях художественной литературы, однако анализ текстов медицинской специальности позволил выявить весомую их нагрузку и в научном (медицинском) тексте, во многом это обусловлено тем, что сложноподчиненное предложение в «структуре научного текста выполняет контактоустанавливающие, прагматические, квалификативные, импрессивно-волюнтативные и другие функции» [7; с. 207].

\section{Список литературы}

1. Аксенова Е.Д., Мирзоева В.М., Мирзоева Е.З. Модальность научного (медицинского) текста (на материале текстов оториноларингологии // Современные исследования социальных проблем. 2016. № 4-1 (28). С. 154-161.

2. Бартон М. Болезни уха, горла, носа. М.: Бином, 2002. 284 с.

3. Бронштейн А., Лемперт Т. Головокружение. М.: ГОЭТАР-Медиа, 2010. 216 c.

4. Виноградов В. В. Основные вопросы синтаксиса предложения (на материале русского языка) // Виноградов В. В. Избранные труды. Исследования по русской грамматике. М.: Наука, 1975. С. 254-294.

5. Лихачев А.Г. Справочник по оториноларингологии. М.: Медицина, 1984. $366 \mathrm{c}$. 
6. Максимов Л.Ю. О порядке частей в сложноподчиненном предложении // Русский язык в школе. 1968. №1. С. 98.

7. Мирзоева В.М., Кузнецова А.А., Мирзоева Е.З. Коммуникативно-прагматическая функция сложных предложений в диалогической структуре текстов медицинской специальности // Вестник Тверского государственного университета. Серия «Филология». 2017. №1. C. 207-211.

8. Русская грамматика. В 2 т. [Под ред. Н. Ю. Шведовой] Т. 2: Синтаксис. М.: Наука, 1980. 714 с.

9. Хронический тонзиллофарингит и информационные технологии его доказательства / Портенко Г.М., Портенко Е.Г., Мирзоева Е.3., Шматов Г.П. Тверь: РИУ ТГМУ, 2017. 197 с.

\section{References}

1. Aksenova E.D., Mirzoeva V.M., Mirzoeva E.Z. Sovremennye issledovaniya social’nyh problem. 2016. № 4-1 (28). P. 154-161.

2. Barton M. Bolezni uha, gorla, nosa [Diseases of the ear, throat, nose]. M.: Binom, 2002. 284 p.

3. Bronshtejn A., Lempert T. Golovokruzhenie [Dizziness]. M.: GOETAR-Media, 2010. 216 p.

4. Vinogradov V.V. Izbrannye trudy. Issledovaniya po russkoj grammatike [Selected works. Research on Russian grammar]. M.: Nauka, 1975. P. 254-294.

5. Lihachev A.G. Spravochnik po otorinolaringologii [Handbook of otorhinolaryngology]. M.: Medicina, 1984. 366 s.

6. Maksimov L.Yu. Russkij yazyk v shkole. 1968. №1. P.98.

7. Mirzoeva V.M., Kuznecova A.A., Mirzoeva E.Z. Vestnik Tverskogo gosudarstvennogo universiteta. Seriya «Filologiya». 2017. №1. P. 207-211.

8. Russkaya grammatika [Russian grammar]/ ed. N. YU. SHvedova. Vol. 2: Sintaksis [Syntax]. M.: Nauka, 1980. 714 p.

9. Portenko G.M., Portenko E.G., Mirzoeva E.Z., Shmatov G.P. Hronicheskij tonzillofaringit i informacionnye tekhnologii ego dokazatel'stva [Chronic tonsillopharyngitis and information technologies for its proof]. Tver': RIU TGMU, 2017. 197 p. 


\section{ДАННЫЕ ОБ АВТОРАХ}

Мирзоева Валентина Михайловна, заведующая кафедрой русско-

го языка; кандидат филологических наук; доцент

Тверской государственный медицинский университет

ул. Советская, 4, г. Тверь, 170100, Российская Федерачия

Аксенова Екатерина Дмитриевна, доцент кафедры русского языка; кандидат филологических наук; доцент Тверской государственный медицинский университет ул. Советская, 4, г. Тверь, 170100, Российская Федераџия katrintver@mail.ru

Мирзоева Евгения Залимовна, ассистент кафедры оториноларингологии; кандидат медицинских наук

Тверской государственньій медицинский университет ул. Советская, 4, г. Тверь, 170100, Российская Федераџия

\section{DATA ABOUT THE AUTHORS}

Mirzoeva Valentina Mikhaylovna, Head of the Chair of Russian language, Candidate of philological sciences, Senior lecturer Tver State Medical University

4, Sovetskaya str., 4, Tver, 170100, Russian Federation

Axenova Ekaterina Dmitrievna, Senior lecturer of the Chair of Russian Language, Candidate of philological sciences, Senior lecturer Tver State Medical University

4, Sovetskaya str., 4, Tver, 170100, Russian Federation katrintver@mail.ru

Mirzoeva Evgeniya Zalimovna, assistant of the Chair of Otorinolaringology, Candidate of medical sciences

Tver State Medical University

4, Sovetskaya str., 4, Tver, 170100, Russian Federation 